\title{
Conf- $941144--25$
}

PNL-SA-24557

NEW NANOPHASE IRON-BASED CATALYSTS FOR HYDROCRACKING APPLICATIONS
D. W. Matson
D. M. Camaioni
J. C. Linehan
S. T. Autrey
J. G. Darab
E. Lui

November 1994

Presented at the

Materials Research Society Annual Fall 1994 Meeting

November 28 - December 2, 1994

Boston, Massachusetts

Prepared for

the U.S. Department of Energy

under Contract DE-AC06-76RLO 1830

Pacific Northwest Laboratory

Richland, Washington 99352

\section{DISCLAIMER}

This report was prepared as an account of work sponsored by an agency of the United States Government. Neither the United States Government nor any agency thereof, nor any of their employees, makes any warranty, express or implied, or assumes any legal liability or responsibility for the accuracy, completeness, or usefulness of any information, apparatus, product, or process disclosed, or represents that its use would not infringe privately owned rights. Reference herein to any specific commercial product, process, or service by trade name, trademark, manufacturer, or otherwise does not necessarily constitute or imply its endorsement, recommendation, or favoring by the United States Government or any agency thereof. The views and opinions of authors expressed herein do not necessarily state or reflect those of the United States Government or any agency thereof. 


\section{DISCLAIMER}

Portions of this document may be illegible in electronic image products. Images are produced from the best available original document. 


\title{
NEW NANOPHASE IRON-BASED CATALYSTS
} FOR HYDROCRACKING APPLICATIONS

\author{
DEAN W. MATSON, JOHN C. LINEHAN, JOHN G. DARAB, DONALD M. CAMAIONI, \\ S. THOMAS AUTREY, AND ED LUI \\ Pacific Northwest Laboratory [1], PO Box 999, Richland, WA 99352
}

\begin{abstract}
Carbon-carbon bond cleavage catalysts produced in situ at reaction conditions from nanocrystalline hydrated iron oxides, show high activity and selectivity in model compound studies. Two highly active catalyst precursors, ferric oxyhydroxysulfate (OHS) and 6-line ferrihydrite, can be produced by a flow-through hydrothermal powder synthesis method, the Rapid Thermal Decomposition of precursors in Solution (RTDS) process. Model compound studies indicate that both catalyst precursors are active at a $400^{\circ} \mathrm{C}$ reaction temperature, but that there are significant differences in their catalytic characteristics. The activity of 6-line ferrihydrite is highly dependent on the particle (aggregate) size whereas the activity of the OHS is essentially independent of particle size. These differences are attributed to variations in the crystallite aggregation and particle surface characteristics of the two catalyst precursor materials. Catalytic activity is retained to lower reaction temperatures in tests using OHS than in similar tests using 6-line ferrihydrite.
\end{abstract}

\section{INTRODUCTION}

Essentially all processes in the petrochemical industry initially involve cleavage of the carbon-carbon bonds in complex organic molecules to produce simpler, lower molecular weight products. To be economically viable, these processes must be catalytically enhanced to speed up reaction rates, lower temperatures required for reaction, and to selectively cleave bonds to produce a desirable product distribution. Traditional hydrocracking catalysts, many of which are based on noble or other transition metals, tend to be both very expensive and highly toxic. Consequently, catalyst fabrication, recovery, recycling, and storage can all affect the economic viability of hydrocracking operations [2]. Development of highly efficient iron-based materials for processes involving carbon-carbon bond cleavage, including petroleum hydrocracking and coal liquefaction, offers the potential for decreasing catalyst costs as well as reducing the need for expensive catalyst recovery and recycling steps. Furthermore, if active iron-based catalysts can be produced containing ultrafine crystallites and high surface areas (i.e., having a large percentage of the iron on a catalytically active surface site), lower catalyst loading requirements may be achieved.

At the Pacific Northwest Laboratory (PNL) we are investigating the activities of ironbased powders as catalytic precursors in hydrocracking reactions and are developing new methods for producing iron-based nanocrystalline powders exhibiting the greatest catalyst potential. PNL's powder forming processes include the Rapid Thermal Decomposition of precursors in Solution (RTDS) process [3-5], a flow-through hydrothermal method, and the Modified Reverse Micelle (MRM) process [5], which uses microemulsion technology to precipitate ultrafine powders. Because these synthesis methods produce powders containing crystallite sizes in the nanometer size range, for certain precursor phases, conversion of these precursor powders to the active catalyst occurs rapidly under the conditions present in the reaction vessel. Using model compound studies we have previously demonstrated that iron-based powders generated by both the RTDS and MRM methods can produce highly active carboncarbon bond scission catalysts under reaction conditions relevant to coal liquefaction processes [5]. In this paper we present recent results of model compound studies obtained using two of the more active catalyst precursor materials, 6-line ferrihydrite and ferric oxyhydroxysulfate, both of which have been produced by the RTDS method. We also attempt to relate powder characteristics to measured activity and use the results as a basis for mechanistic interpretation of the catalytic process. 


\section{CATALYST PRECURSOR SYNTHESIS AND EVALUATION}

The RTDS continuous powder synthesis method involves formation of ultrafine solid particles by reaction of a solute species when pressurized homogeneous solutions are passed rapidly through a heated linear reactor (1-30 sec residence time) and then abruptly quenched by dropping the pressure. When using aqueous solvents for this process, well-known hydrothermal reactions leading to formation of oxides or hydroxides occur between metal-containing precursor solute species and the solvent itself [6]. Multiple-metal and/or doped oxide/oxyhydroxide powders can be easily produced by the appropriate choice and loadings of precursor solute species. RTDS products are collected as suspensions, and typically contain submicrometer-sized aggregates of nano-scale crystallites. The solid powders can be separated from the suspension by centrifugation, spray drying, or freeze drying. Details of the RTDS process have been presented elsewhere [3-5].

Six-line ferrihydrite is a poorly defined ferric oxyhydroxide phase named for the number of broad lines present in its powder X-ray diffraction pattern and is believed to be a hydrated substructure of hematite $\left(\alpha-\mathrm{Fe}_{2} \mathrm{O}_{3}\right)$ [7]. RTDS synthesis of this material was accomplished using feed solutions containing ferric nitrate $(0.1 \mathrm{M})$ and urea $(0.5 \mathrm{M})$. Under the hydrothermal conditions present in the reaction tube $\left(-300^{\circ} \mathrm{C}, 4000-8000\right.$ psi pressure) the urea rapidly decomposes and reacts with the solvent to generate ammonia and carbon dioxide, creating a basic solution. The particulate product formed and collected in the RTDS suspension was similar in appearance, but crystallographically and catalytically distinct from material generated by adding ammonia directly to ferric nitrate solutions at ambient conditions. At higher processing temperatures or at the same RTDS processing conditions but without urea, hematite is the predominant iron oxide phase produced.

Ferric oxyhydroxysulfate (OHS) is a poorly crystallized variation of akaganeite $(\beta-\mathrm{FeOOH})$, that contains tunnel structures in which chloride ions reside. In OHS some or all of the chloride ions are replaced by sulfate ions. OHS is formed naturally by bacterial oxidation of $\mathrm{Fe}(\mathrm{II})$ in acidic mine waters, or by a laboratory procedure involving low yields and a lengthy (30 day) dialysis step [7]. OHS was synthesized using the RTDS process by a low temperature reaction $\left(100-150^{\circ} \mathrm{C}\right)$ of solutions containing the ferric and sulfate ions, followed by a brief period of dialysis ( $<7$ days).

Both the 6-line ferrihydrite and OHS phases can be produced using standard laboratory syntheses [7] and powders produced by those methods have been shown to be catalytically active for carbon-carbon bond cleavage reactions [8]. However, bench-top syntheses of these materials are batch processes that are not necessarily scalable to larger batch sizes, and both require lengthy dialysis steps that can be reduced or avoided by using the continuous RTDS method.

The RTDS-generated catalyst precursor powders discussed here were separated from the liquid phase by sedimentation/centrifugation. The solids were dried, first under flowing nitrogen, then in a vacuum drying oven at $<100^{\circ} \mathrm{C}$. The products were ground in an agate mortar where appropriate and sieved into three fractions: -325 mesh, $+325 /-230$ mesh, and +230 mesh. Powders were characterized for phase and crystallite size by powder X-ray diffraction and for agglomerate size and shape by electron microscopy (SEM and TEM). Catalytic characteristics were evaluated by measuring the powder's ability to promote consumption of model organic compounds, including naphthyl bibenzylmethane (NBBM) and a series of diphenylmethane (DPM) derivatives (Fig. 1). Model compounds used for these studies were determined to be 99\% pure or better by gas chromatography (GC) and NMR analysis. The catalyst test procedure consisted of loading fixed amounts of catalyst precursor, elemental sulfur, model compound, and 9,10-dihydrophenanthrene (a hydrogen donor solvent) in Pyrex tubes, sealing under vacuum, emersing in a fluidized sand bath for one hour, and analyzing the product distribution by GC [5].
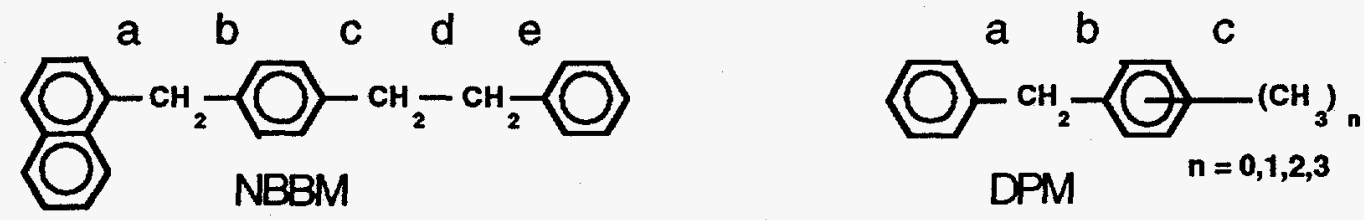

Figure 1. Model compounds used to evaluate catalytic activity of RTDS-derived powders. 


\section{RESULTS AND DISCUSSION}

Electron micrographs of RTDS-generated OHS and 6-line ferrihydrite powders are presented in Figures 2 and 3. The OHS powders contain micrometer-sized agglomerates made up of submicrometer-sized spherical features (Fig. 2a). At higher resolutions obtained using TEM, the spherical features clearly do not have smooth surfaces, but rather are very irregular and consist of elongated crystallites extending outward from the sphere surface (Fig. 2b). SEM micrographs of sieved samples of RTDS-generated 6-line ferrihydrite (Fig. 3) suggest a much denser material than the OHS. Dark-field TEM micrographs of the 6-line ferrihydrite powders indicate that they consist of densely packed nanocrystallites. The higher microstructural density and strength of inter-crystalline agglomeration of the 6-line material was also reflected in its greater tendency to form hard masses on drying, requiring much greater effort to grind and sieve into the smaller fractions than the OHS. These obvious physical differences in particle morphology may play a significant role in determining the differences in catalytic capabilities of the two precursor materials, as discussed below.
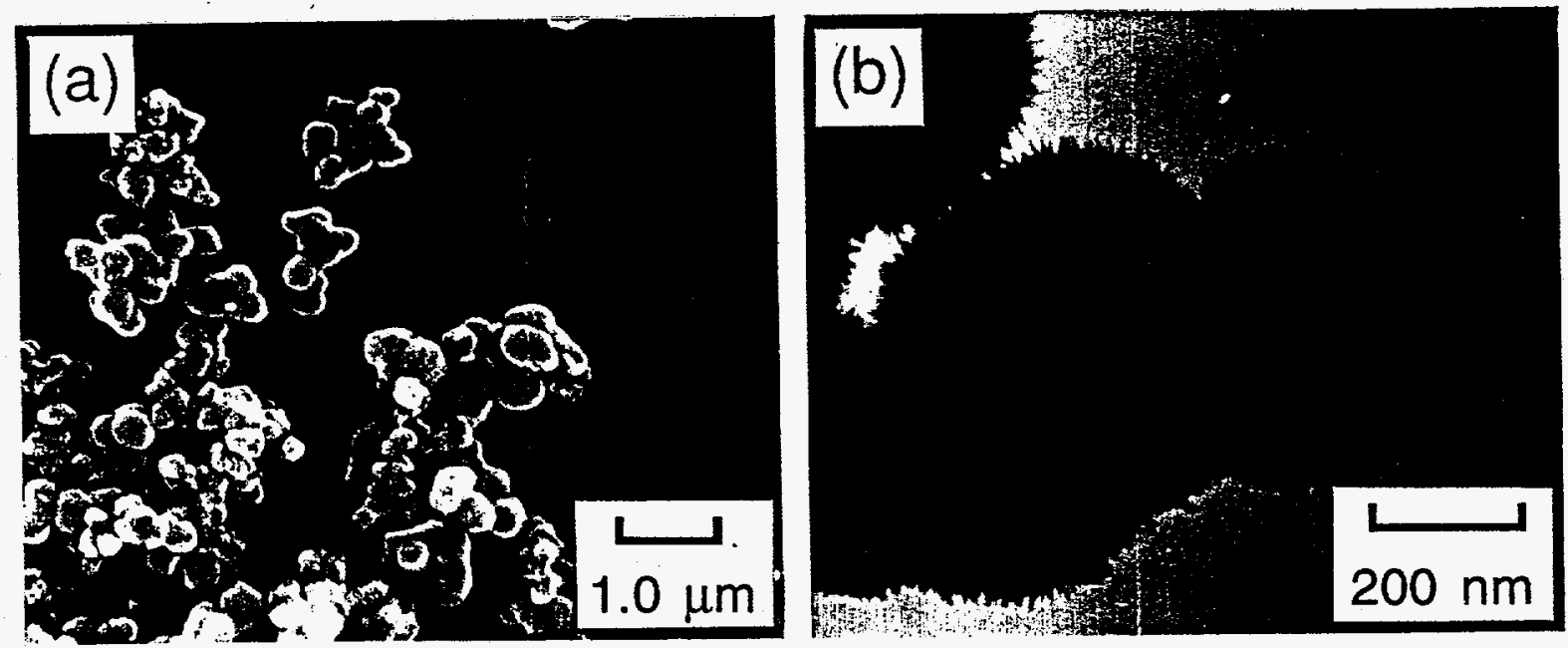

Figure 2. a) SEM micrograph of OHS powder produced by RTDS. b) TEM micrograph of the surfaces of the particles shown in Fig. $2 \mathrm{a}$.
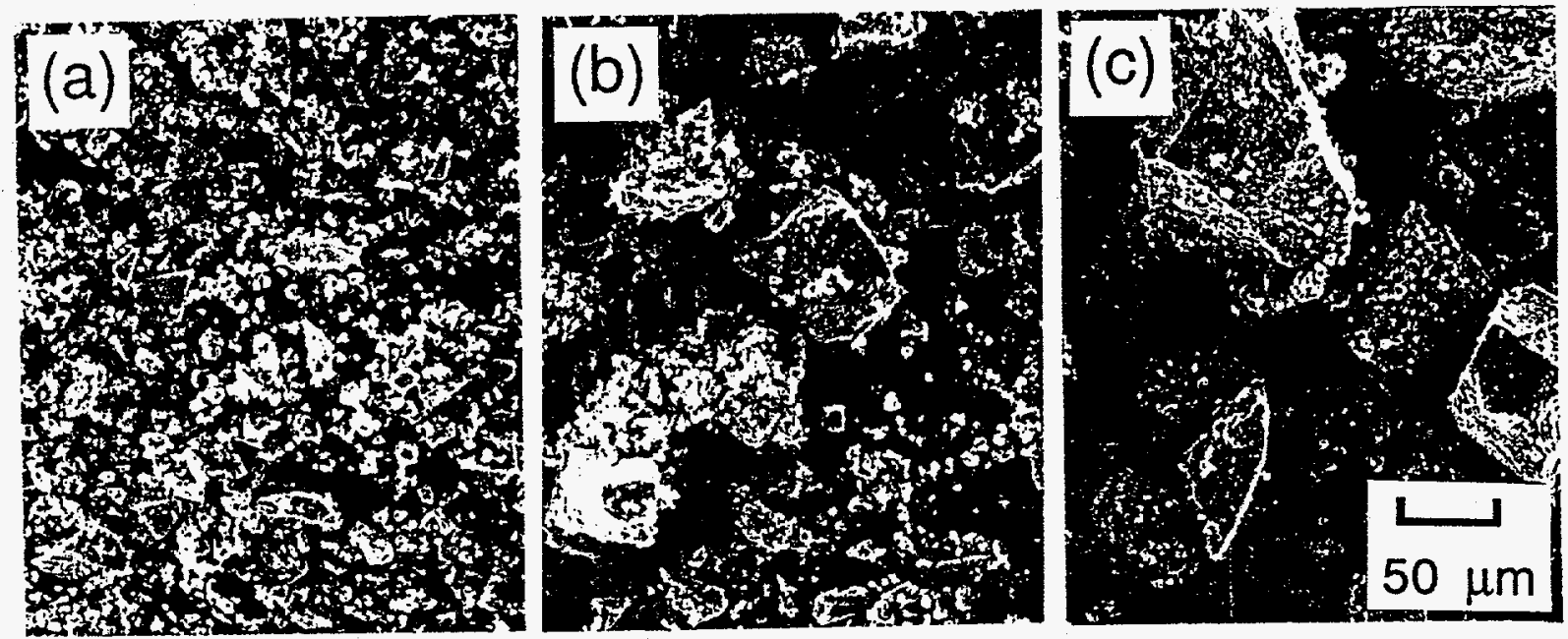

Figure 3. SEM micrographs of sieved 6-line ferrihydrite powder produced by RTDS. a) -325 mesh, b) $-230 /+325$ mesh, c) +230 mesh. 
The results of catalyst precursor screening of RTDS-generated powders using the model compound substrate naphthyl bibenzylmethane (NBBM) are shown in Table I. In addition to 6line ferrihydrite and OHS, RTDS hematite (which is produced under the same RTDS conditions as 6-line ferrihydrite but in the absence of the urea in the feedstock solution) is included for reference. The Table also includes a thermal background value for consumption of the model compound under test conditions in the absence added catalyst or elemental sulfur. In contrast to uncatalyzed thermal consumption of NBBM, in which essentially no selective bond cleavage was observed, NBBM consumption catalyzed by the iron-based materials preferentially cleaved bonds " $a$ " and "b". Product distributions from catalyzed NBBM reactions yielded naphthalene, methylbibenzyl, methyl naphthalene, and bibenzyl almost exclusively.

Table I. Consumption of Naphthyl Bibenzylmethane in the Presence of Iron-Based Catalyst Precursors Produced by the RTDS Methoda

\begin{tabular}{|l|c|c|}
\hline Precursor Phase & NBBM Consumed (\%) & Selectivity \\
\hline \hline none & $3 \pm 2^{\mathrm{c}}$ & $40-60$ \\
\hline Ferric Oxyhydroxysulfate & $>90^{\mathrm{d}}$ & 97 \\
\hline 6-line Ferrihydrite & $>90$ & 97 \\
\hline Hematite & 39 & 85 \\
\hline
\end{tabular}

aTest conditions: $3 \mathrm{mg}$ catalyst precursor (-325 mesh), $3 \mathrm{mg}$ elemental sulfur, $25 \mathrm{mg}$ model compound, $100 \mathrm{mg}$ 9,10-dihydrophenanthrene, $400^{\circ} \mathrm{C}, 1 \mathrm{hr}$.

bSelectivity defined as products of $a$ and $b$ bond cleavage as a percentage of products from total bonds cleaved. cNo sulfur added. Addition of sulfur without adding iron-based precursor yielded sulfur containing organic products. dModel compound consumptions in excess of $90 \%$ were uncalibrated.

The results presented in Table I suggest that both OHS and 6-line ferrihydrite are excellent catalysts for the consumption of NBBM under the test conditions used. In previous work, however, we showed that the activity of RTDS-generated 6-line ferrihydrite as a dispersed catalyst precursor for the consumption of NBBM was strongly dependent on the particle (agglomerate) size of the precursor powder [9]. In fact, the majority of the catalytic activity observed for bulk ferrihydrite powders was attributed to a very small weight fraction of the starting material having the smallest particle sizes. These results suggested that mass transport limitations are an important consideration even in "nanocrystalline" materials, depending on the degree of the crystallite agglomeration. They also emphasized the distinction between crystallite size and the implied catalyst "dispersibility" in a reaction medium and the importance of comparing comparably sized and characterized powders when evaluating catalytic activities.

The effect of particle sieve size on activity of OHS as a catalyst precursor toward consumption of NBBM was also investigated. The results, shown in Figure 4, suggest little or no relationship between the observed catalytic activity and particle size for this material as was seen for the 6-line ferrihydrite. This lack of observed particle size/activity effect may result from the more open surface structure of the OHS particles (Fig. 2b) and/or weaker crystallite/crystallite interactions holding the agglomerated particles together. Evidence for the latter may be found in the fact that OHS required little or no grinding in order to accomplish sieving to the smaller particle sizes.

In addition to particle size/activity effects, dissimilarities were noted in the effect of reaction temperature on the catalytic activities of OHS and 6-line ferrihydrite. Although activities of both materials toward the consumption of NBBM dropped at reaction temperatures below $400^{\circ} \mathrm{C}$, the 6-line ferrihydrite activity fell off more quickly. OHS retained measurable catalytic activity to temperatures as low as $250^{\circ} \mathrm{C}$. We speculate that the free energy required for conversion of OHS to the active iron sulfde catalyst is lower than the corresponding energy for conversion of the 6-line ferrihydrite.

When OHS and 6-line ferrihydrite were evaluated as catalytic precursors for the consumption of the model compounds diphenylmethane and its methylated analogs (Fig. 1), the 
extent of reaction increased with degree of methyl substitution (Fig. 5). Products of the catalyzed reactions were almost exclusively the result of bond " $b$ " cleavage in the methylated analogs. Toluene and methylated aromatic species derived from the substituted ring were the major products from the catalyzed reactions. The general increase in reaction rate of the model compounds having a systematically decreasing oxidation potential suggests that a redox mechanism may provide a rate determining step in the catalytic consumption of these species. Note that in the absence of catalyst, there was no corresponding correlation between consumption and degree of methyl substitution.

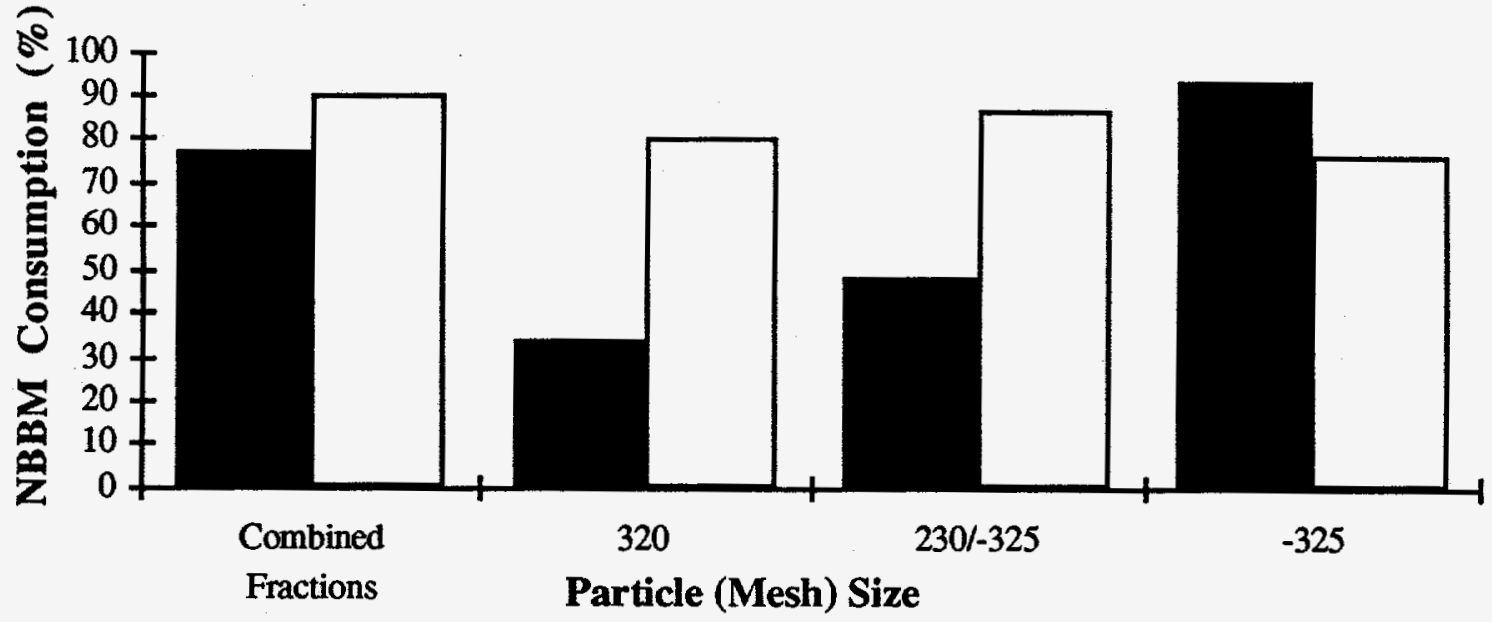

Figure 4. Comparison of the effect of particle size between 6-line ferrihydrite (white) and OHS (black) on the consumption of the NBBM model compound. Reaction conditions for 6-line ferrihydrite runs were the same as those used to obtain results shown in Table 1 except that reaction temperatures for the $\mathrm{OHS}$ runs were $360^{\circ} \mathrm{C}$.

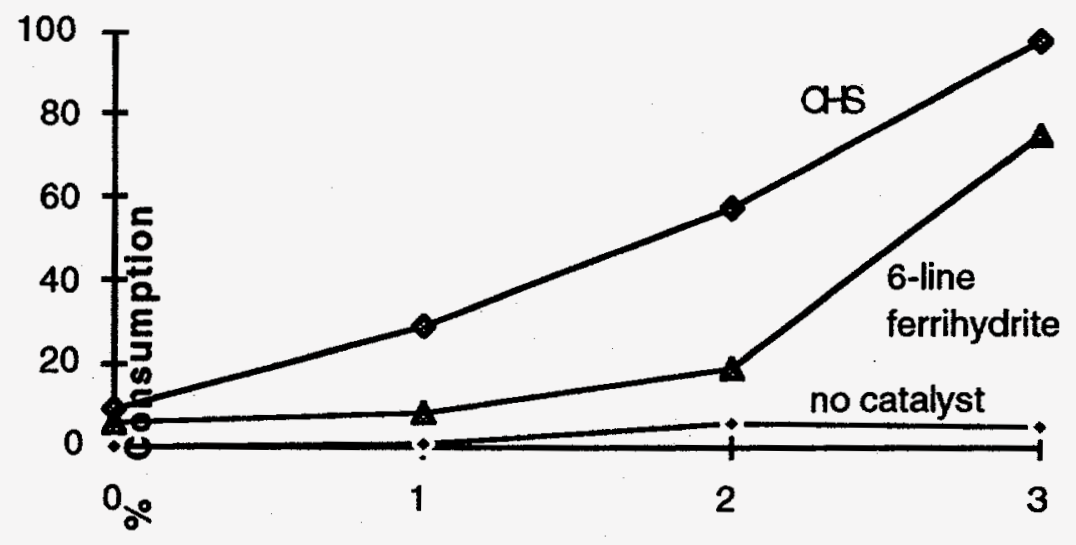

No. of Substituted Methyl Groups on DPM

Figure 5. Consumption of diphenylmethane (DPM) and its methylated analogs (at $400^{\circ} \mathrm{C}, 1 \mathrm{hr}$ reaction time, with elemental sulfur and 9,10-dihydrophenanthrene) in the presence of 6-line ferrihydrite, OHS, and no catalyst. Oxidation potentials of the model compounds decrease with increasing methyl substitution. 


\section{SUMMARY}

The RTDS process can be used to produce highly active nanocrystalline iron-based catalyst precursor powders for hydrocracking applications. The two most active phases, ferric oxyhydroxysulfate and 6-line ferrihydrite, transform into active catalysts in situ under liquefaction conditions in the presence of elemental sulfur and a hydrogen donor. As dispersed heterogeneous catalyst precursors, the activity of the 6-line ferrihydrite phase is sensitive to the particle size whereas the oxyhydroxysulfate phase is not. This difference is attributed to major differences in the packing characteristics of individual crystallites in the particles making up the powders of the two materials. Individual crystallites in the oxyhydroxysulfate powders extend from the surfaces of spherical aggregates, with considerable surface area exposed to the solvent and model compound substrate molecules. Crystallites in the 6-line ferrihydrite powder particles are packed into dense aggregates. Differences between the effects of particle size and activity for these materials likely can be attributed to differences in the dispersibility and accessibility of active catalyst surfaces. Increasing activity of the iron-based precursor powders toward diphenylmethane with increasing methyl group substitution suggests that a redox mechanism may play the role of a rate limiting step in the bond cleavage reactions in these substrates.

\section{ACKNOWLEDGMENTS}

The authors gratefully acknowledge the following PNL staff for their assistance: G.E. Fryxell, J.E. Coleman, H.T. Schaef, and D.E. McCready. This work was supported by the U.S. Department of Energy, Office of Fossil Energy. Support for E.L was provided by the Associated Western Universities, Inc., Northwest Division under Grant DE-FG06-89ER-75522 with the U.S. Department of Energy.

\section{REFERENCES}

1. Pacific Northwest Laboratory is operated for the United States Department of Energy by the Battelle Memorial Institute under contract DE-AC06-76RLO 1830.

2. J.A. Rabo in Advanced Heterogeneous Catalysts for Energy Applications Vol. II, U.S. DOE report DOE/ER-30201-H1, p. 1.1 (1994)

3. D.W. Matson, J.C. Linehan, and R.M. Bean, Mater. Lett. 14, 222 (1992).

4. J.G. Darab, M.F. Buehler, J.C. Linehan, and D.W. Matson in Better Ceramics Through Chemistry VI, edited by A.K. Cheetham, C.J. Brinker, M.L. Mecartney, and C. Sanchez (Mat. Res. Soc. Symp. Proc. 346, Pittsburgh, PA, 1994) pp. 499-504.

5. D.W. Matson, J.C. Linehan, J.G. Darab, and M.F. Buehler, Energy and Fuels 8, 10 (1994).

6. W.J. Dawson, Ceram. Bull. 67, 1673 (1988).

7. U. Schwertmann and R.M. Cornell, Iron Oxides in the Laboratory: Preparation and Characterization (VCH Publishers, Inc., New York, 1991).

8. J.C. Linehan, D.W. Matson, and J.G. Darab, Energy and Fuels 8, 56 (1994).

9. J.G. Darab, J.C. Linehan, and D.W. Matson, Energy and Fuels 8, 1004 (1994). 